\title{
Sowing the Seeds of Neuroscience Middle School Curriculum Program: Learning about the Nervous System Using Medicinal Plants
} \author{
Pasadena, CA; ${ }^{5}$ data2insight LLC, Seattle, Washington. \\ Keywords: Science Literacy, Plants, Invertebrates, Culture, Middle School \\ Publication Date: October 3, 2018 \\ DOI: https://doi.org/10.15695/jstem/v1i1.21
}

Eric H. Chudler ${ }^{1,2}$, Kristina M. Straus ${ }^{1,3}$, Enrique C. Orlina ${ }^{4}$, and Veronica S. Smith ${ }^{5}$

${ }^{1}$ Department of Bioengineering; ' ${ }^{2}$ Department of Anesthesiology \& Pain Medicine; ${ }^{3}$ Program on the Environment, University of Washington; ${ }^{4}$ Rocinante Research,

\begin{abstract}
Educators are increasingly looking to neuroscience for guidance to improve classroom instruction and to teach their students about the nervous system. Although materials to assist teachers are available, many educators still have misconceptions about the brain. Twenty-three middle school teachers were trained to use the Sowing the Seeds of Neuroscience (neuroseeds.org) curriculum in their sixth, seventh, and eighth grade classrooms. The novel, hands-on, interactive lessons are aligned with Next Generation Science Standards and Common Core standards. The curriculum uses the "5E" model of instruction to study the neuroactive properties of plants and increase students' neuroscience literacy. The lessons are designed to be culturally responsive by encouraging students to bridge their home and school experiences through an examination of medicinal plants used by their families, communities, and/or ancestors. Student pretest-posttest $(\mathrm{N}=1,240)$ results revealed that students significantly improved their neuroscience content knowledge after participating in the Sowing the Seeds of Neuroscience curriculum program. These findings suggest that this curriculum program is a promising resource for middle school educators who want to improve their students' neuroscience literacy.
\end{abstract}

\section{INTRODUCTION}

Public interest in the field of neuroscience has expanded greatly in the past two decades. During this time, many discoveries from neuroscience laboratories across the world have made magazine covers, newspaper headlines, and television news stories. Educators, looking for the best methods to improve their teaching, have often turned to neuroscience for answers (Blackwell et al., 2007; Pickering and Howard-Jones, 2007). Despite the great public interest in neuroscience, misunderstandings and misconceptions about the brain are common (Dekker et al., 2012; Howard-Jones, 2014). Herculano-Houzel (2002) found that high school students, college students and college graduates incorrectly answered questions about brain size, the role of emotions in decision-making, and memory storage. The erroneous assumption that we use only $10 \%$ of the brain (Beyerstein, 1999) was also common in this study population. Educators harbor similar misconceptions about the nervous system. A majority of teachers in one survey were unsure if mental activity originates from brain function, and only $10 \%$ of the 158 teachers surveyed disagreed with the statement "We mostly only use $10 \%$ of our brains" (Howard-Jones, 2009, 2010).

Cameron and Chudler (2003) discuss the importance of neuroscientific literacy to young students. For example, knowledge about the brain may help reduce the stigma attached to mental and neurological illnesses. Lifestyle choices (e.g., drug abuse, adherence to prescription medication, risk-taking behavior) may be influenced by students' understanding of the nervous system and the consequences of damage to the brain. Student knowledge about the brain, especially the brain's capacity to change, may also have positive influences on academic performance (Blackwell et al., 2007).

Many existing programs teach students about the effects of drugs on the brain. For example, the National Institutes of Health Office of Science Education distributes two supplements for high school students about drug addiction (Landes and Westbrook, 2000) and sleep (Bybee and Bloom, 2003). The National Institute on Drug Abuse also produces exemplary precollege classroom material about drug abuse (e.g., Brain Power! The NIDA Junior Scientist Program; Mind over Matter). Other resources for precollege classrooms have been developed that focus on addiction, the reward pathway, and drug abuse. For example, BRAINU, an NIH-funded neuroscience education program for grade 5-12 students and teachers (Dubinsky, 2010; MacNabb et al., 2006), includes an excellent hands-on laboratory experiment testing the effects of alcohol on the roundworm C. elegans. 
Valuable online resources for precollege students that address drug abuse have also been created, such as those by the Genetic Science Learning Center (Stark and Pompei, 2010), Center for Technology in Teaching and Learning (Klisch et al., 2012; Miller et al., 2006) and the Pharmacology Education Program (Schwartz-Bloom et al., 2011). In contrast to the wide range of programs that seek to educate students about the brain and drugs, few educational resources discuss the neuroactive properties and medicinal uses of plants and herbs (Straus and Chudler, 2016).

The Sowing the Seeds of Neuroscience curriculum was designed to engage students with hands-on learning, culturally relevant content, and the possibility of real scientific discovery. Previous work has documented that hands-on or "active" learning is a more effective way to teach science (Freeman et al., 2007; Michael, 2006; Taraban et al., 2007) and that such teaching may benefit underrepresented minority students disproportionately (Gordon et al., 2001; Haak et al., 2011). The lessons were designed to be culturally responsive by encouraging students to bridge their home and school experiences through an examination of medicinal plants used by their families, communities, and/ or ancestors. The importance of cultural factors and beliefs to science learning are well documented (Aikenhead and Jegede, 1999). Culturally relevant science teaching involves bridging students' home experiences with their class experiences by bringing elements into their school learning which validate their culture. Such connections may make this curriculum more empowering and exciting to students. Furthermore, this curriculum encourages students to do truly authentic science: to engage in practices similar to those of scientists, including questioning and critical thinking (Chinn and Malhotra, 2002) while, for example, determining which plants to test in which experiment.

Learning experiences prior to high school are essential to encourage students' interest and literacy in science, and have a significant impact on students' success in science (Osborne et al., 2003). In fact, early interest is a stronger predictor than test performance for determining which students become scientists (Tai et al., 2006). Teachers who have taught Sowing the Seeds of Neuroscience report that their students are deeply engaged in the curriculum, exploring plant-based medicines in their classrooms on invertebrate models, and talking with their families about traditional uses of plants. Many students have explored these questions further in science fairs, demonstrating a deep interest in the content or methods used in our curriculum.

The present paper focuses on a novel middle school neuroscience curriculum that is designed to better engage all students resulting in improved neuroscience literacy and attitudes about science. The objective of this education intervention was to improve neuroscience literacy and attitudes toward science for all students. Furthermore, the curriculum developers hypothesized that the culturally relevant, handson curriculum using medicinal plants to teach neuroscience would increase knowledge gains and interest in science at higher rates for underrepresented minority students.

\section{METHODS}

This study was conducted under University of Washington IRB \#43828. All students and teachers consented to participate in this study.

Resource Content. The Sowing the Seeds of Neuroscience curriculum was developed for use by middle school students and consists of eight lessons using the " $5 \mathrm{E}$ " instructional model (Bybee, 1997, 2002; Tanner, 2010; Trowbridge et al., 2004) as a framework. The $5 \mathrm{E}$ model consists of five phases to improve student understanding: engagement, exploration, explanation, elaboration, and evaluation. Each of the eight lessons was also aligned with the Next Generation Science Standards (States, 2013) and the Common Core Mathematical and English Language Arts Standards (National Governors Association Center for Best Practices, 2010a, 2010b). A short description of each of the eight lessons is below.

1. Neuroscience 101: Students will gain a basic understanding of neuroanatomy and neurophysiology. After observing the structure of the brain, spinal cord, and nerve cells, students will model neuroanatomy and neurotransmission.

2. Infusions and Decoctions: Students will learn that many plants contain chemicals with medical and neuroactive properties and explore how plants are used around the world to treat illness and alter brain function. In the laboratory portion, students will make infusions or decoctions that contain these plant chemicals. These extracts will be used in subsequent lessons.

3. If Worms Drank Coffee: Students will be introduced to the ideas that the brain controls the body's movements and that Parkinson's disease is a neurological disorder that affects movement. Students will think about the type of plant extracts that might affect planaria (flatworm) movement and then conduct an experiment to explore planaria movement with and without the addition of a plant extract.

4. Chromatography: Students will investigate how plant extracts are mixtures of many chemical compounds and how the health benefits of a medicinal plant may be due to a single chemical or a combination of chemical compounds working together. Students will use paper chromatography to separate chemical compounds from plant extracts.

5. Botanical Superheroes: Students will learn that bacteria can cause illness, including neurological diseases such as meningitis. In the hands-on portion of the lesson, students will investigate whether plant extracts are effective at inhibiting bacterial growth.

6. Heads and Tails: Students will be introduced to the con- 
cepts of stem cells and regeneration using planaria as a model organism. Students will hear that neuroscience research promotes health and may lead to a better understanding of neurological disease and therapies to treat neurological disorders. In the laboratory portion, students will examine how their plant extracts affect planaria regeneration.

7. Botanical Heart Throbs: Students will learn about stimulants and depressants and then apply this knowledge to an experiment on pulsation rate in Lumbriculus variegatus (blackworm) (Straus and Chudler, 2015). Students will observe and count the Lumbriculus pulsation rate with and without the addition of a plant extract. Students will explore chemical transmission in the nervous system and circulatory system and discover how plant extracts affect the Lumbriculus circulatory system.

8. SpikerBoxes: Students will use inexpensive bioamplifiers called SpikerBoxes (Marzullo and Gage, 2012) to investigate the electrical responses in the cockroach nervous system. The SpikerBox allows students to hear and see action potentials generated by cockroach leg neurons. Students will investigate how plant extracts affect the discharge rate of action potentials.

Curriculum Development. As part of the design phase and prior to dissemination of the lessons within classrooms, six middle school science teachers were trained to use the curriculum during a one-week workshop. Teachers worked though all lessons and provided feedback to improve the usefulness of the materials for their students. These teachers were given kits containing all the materials necessary to implement the lessons in their classrooms during the following academic year. A total of 362 students piloted the lessons during the spring of 2013. Written and oral comments about the lessons from teachers and students were used to further revise the resource. After these revisions, the lessons were placed online at the project web site: www.neuroseeds.org.

Teaching Training. After the curriculum was revised based on the suggestions of the teachers and students who piloted the lessons, new middle school science teachers were recruited. In the 2016-2017 school year, 23 teachers at 14 different Washington State and Oregon schools were recruited to use the Sowing the Seeds of Neuroscience materials in their middle school classrooms. These teachers attended a professional development workshop in either Seattle or Yakima where they were taught about neuroscience and trained to use the equipment and materials. All workshops followed the same core curriculum and all teachers had the opportunity to work through all eight Sowing the Seeds of Neuroscience lessons. The Yakima workshops took place over three days while the Seattle workshops took place over five shorter days and included additional field trips and extension activities. Successful completion of the workshop allowed the teachers to borrow kits to teach the Sowing the Seeds of Neuroscience curriculum in their classrooms in both the present and future school years. These kits contained all the materials necessary to teach the curriculum, including petri dishes, dried medicinal plants, and hot plates. Teachers borrowed the kits for up to 12 weeks and taught the lessons over the course of that period. Teachers were instructed to administer the pretest prior to the first lesson and to administer the posttest no more than 12 weeks after the pretest.

Pretest-Posttest Data Collection. The 23 trained teachers administered a pretest to their students before teaching any lessons and an identical posttest after completion of the lessons and no more than 12 weeks after the pretest. The test included fifteen content knowledge questions about neuroscience, medicinal plants, and model organisms, thirteen questions to assess attitudes about science, and five demographic questions (i.e. grade, gender, ethnicity, race, and language spoken at home; see supplemental materials). Student attitudes about science were measured using a subset of questions from the Simpson-Troost Attitude Questionnaire (STAQ) (Owen et al., 2008).

Student Subjects. A total of 1809 students completed a pretest and 1727 students completed a posttest. From these, it was possible to compile a matched analytic sample of 1245 students who completed both the pretest and posttest. The demographics of the analytic sample are summarized in Table 1.

Data Processing. Student responses to the 15 content knowledge questions were recorded as correct only if the single correct answer was selected on the Scantron form. One point was assigned for each correct answer recorded. Answers were not weighted. If multiple answers or no answer was selected on the Scantron form, the response was recorded as incorrect and zero points were assigned. The overall student content knowledge score was calculated both

Table 1. Student Demographics (N=1240) (number of students $/ \%$ of total sample; missing data are not included).

\begin{tabular}{l|c}
\hline \multirow{3}{*}{ Grade level } & 6th Grade $(597 / 48.1 \%)$ \\
& 7th Grade $(379 / 30.6 \%)$ \\
8th Grade $(255 / 20.6 \%)$
\end{tabular}


as a count and as a percent of items correct based on the number of items marked as correct out of 15 content knowledge test items.

Three of the five scales or domains from STAQ were used in this study:

1. Motivating Science Class scale (six items) measures the student's positive affect toward their science class, particularly with regard to teacher-determined lessons.

2. Self-Directed Effort scale (four items) measures the student's perceptions of their willingness to work hard to do well in science.

3. Science is Fun for Me scale (three items) measures the student's positive affect toward science in general.

Students' scores for each of the three domains were calculated by averaging their responses to each of the items in that domain. Due to the limited number of items measuring each scale, each attitude scale score was calculated only if there were no missing responses for the student. Higher scores indicated a more positive attitude.

Statistical Analysis. Statistical analyses were performed using the Stata statistical software package, including paired t-tests and effect size calculations, to compare pretest and posttest scores of the four outcome measures (one content knowledge and three attitude measures) for the full matched sample and then by each participating teacher. Regression models were run to investigate the potential associations between content knowledge scores and student demographic, school, and teacher/classroom attributes. The model chosen was a regression of students' content knowledge posttest scores on their pretest scores, grade level, gender, ethnicity, race, language spoken at home, school type, teacher experience teaching Sowing the Seeds of Neuroscience (in years) and the number of Sowing the Seeds of Neuroscience lessons taught. A quality assurance check of the statistical analyses was performed, which consisted of a second quantitative analyst reviewing the assumptions and the syntax developed to run the analysis and validating the outcomes for a subset of students and classrooms.

The regression models take the following general form:

post-test $=\beta_{0}+\beta_{1}$ pretest $+\delta_{1} G R A D E+\delta_{2}$ GENDER + $\delta_{3}$ ETHNICITY $+\delta_{4} R A C E+\delta_{5} H O M E L A N G+\delta_{7} S C H T Y P E$ $+\beta_{2}$ nyrstch $+\beta_{3}$ nlessons $+u$

where $\beta_{0}$ is the intercept (constant term), $\beta_{1}$ is the regression coefficient for pretest scores, $\beta_{2}$ is the regression coefficient for the number of years that the students' teachers have been teaching the Sowing the Seeds of Neuroscience unit, $\beta_{3}$ is the regression coefficient for the number of Sowing the Seeds of Neuroscience units the students' teachers taught this year, and the $\delta_{\mathrm{i}}$ are regression coefficients for dummy variables that represent the categories for each of the student and school attributes.

The grade category variable was collapsed to be a simple indicator for sixth graders to improve performance of the regression model, particularly with regard to multicollinearity. The school setting categorical variable was dropped from the model to correct for multicollinearity with the teacher attributes that were added to account for how the Sowing the Seeds of Neuroscience instruction was delivered. A post-estimation analysis of variance inflation factors suggests that the level of multicollinearity in these models is not a problem.

\section{RESULTS}

Students in grades six through eight correctly answered significantly more science content knowledge questions at posttest compared to pretest. The average correct pretest score for all students was $54.1 \%$ compared to an average correct posttest score of $69.3 \%$. This difference represents a statistically significant increase in content knowledge $(\mathrm{t}=29.08$, $\mathrm{df}=1244, \mathrm{p}<0.01$; Figure 1). A Cohen's $\mathrm{d}=0.82$ effect size was calculated to determine the magnitude of the observed difference from pretest to posttest. The observed effect size exceeds Cohen's convention for a large effect $(\mathrm{d}=0.80)$.

Not all teachers taught all lessons during the 12-week period: the number of lessons taught ranged from two to seven

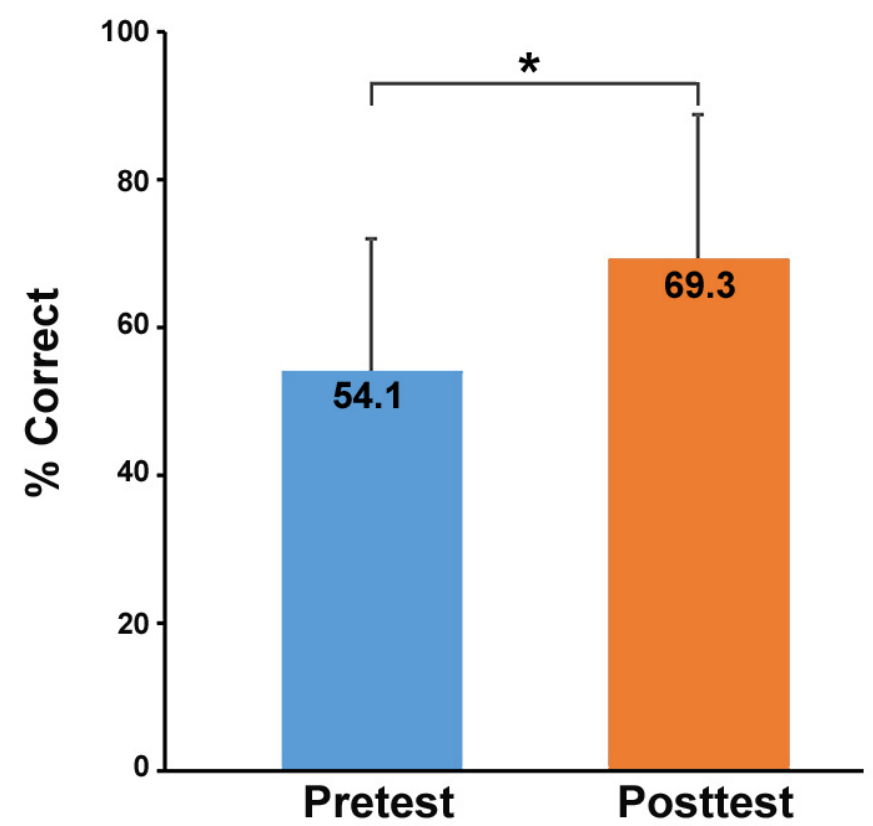

Figure 1. Overall student content knowledge, percent correct, before (pretest) and after (posttest) using the Sowing the Seeds of Neuroscience lessons based on grade level. Significant gains in the number of correct science content knowledge questions were observed on the posttest compared to the pretest when students from all grades were grouped together. $(*=p<0.01)$. Error bars indicate standard deviation. 
with a mean and mode number of lessons taught of 4.5 and 4 , respectively. The most commonly included lessons were Neuroseeds 101 (taught by 22 teachers), Infusions and Decoctions (taught by 21 teachers), and If Worms Drank Coffee (taught by 20 teachers).

Regression models were run to investigate the potential associations between content knowledge scores and student

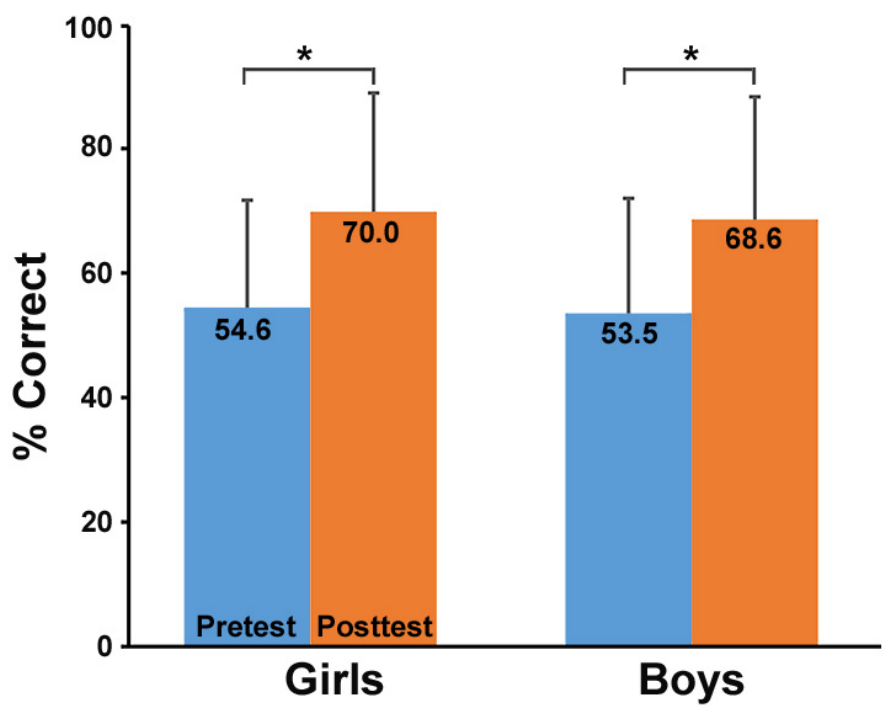

Figure 2. Student content knowledge before (pretest) and after (posttest) using the Sowing the Seeds of Neuroscience lessons based on gender. Both boys and girls correctly answered more questions on the posttest than on the pretest $(*=p<0.01)$ but there were no significant differences between the total percent correct answers between boys and girls on either the pretest or the posttest. Error bars indicate standard deviation.

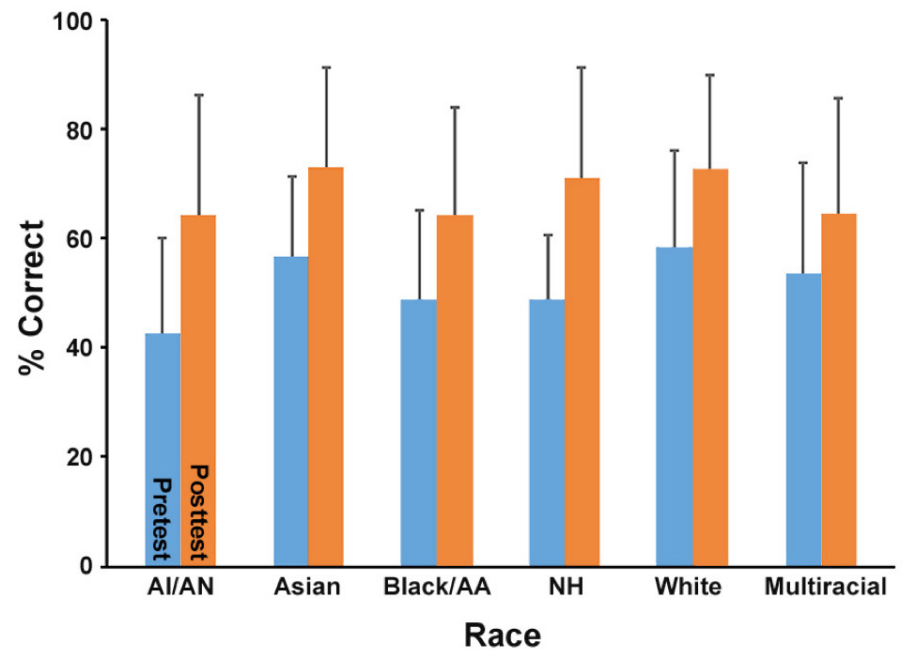

Figure 3. Student content knowledge before (pretest) and after (posttest) using the Sowing the Seeds of Neuroscience lessons based on self-reported race. AI/AN = American Indian/Alaska Native; AA = African American; $\mathrm{NH}=$ Native Hawaiian/Pacific Islander. Each bar indicates the percent correct before and after the Neuroseeds lessons were used by students of different self-reported races. Error bars indicate standard deviation. demographic, school, and teacher/classroom attributes (Table 2 and Table 3). A regression model of students' content knowledge posttest scores on their pretest scores, grade level, gender, ethnicity, race, language spoken at home, school type, teacher experience teaching Sowing the Seeds of Neuroscience (in years), and the number of lessons taught was significant $(F[16,1061]=37.7, p<0.001)$, with an adjusted coefficient of determination $\left(\mathrm{R}^{2}\right)$ of 0.353 . This indicates that approximately $35.3 \%$ of the variation in the dependent variable - posttest content knowledge — is predictable from the independent variables in the model. Most of the explanatory power of the model can be attributed to controlling for pretest scores $(\beta=0.55, \mathrm{SE}=0.03)$. In addition, several student attributes were found to be significant predictors of content knowledge at posttest, including sixth grade $(\delta=9.10$, $\mathrm{SE}=1.05)$, Black or African American $(\delta=-3.98, \mathrm{SE}=1.66)$, Multiracial $(\delta=-5.11, \mathrm{SE}=1.24)$, and speaking multiple languages at home $(\delta=-4.56, \mathrm{SE}=1.33)$. Both of the teacher/ classroom attributes included in the model (number of years teaching the lessons $[\beta=1.69, \mathrm{SE}=0.57]$ and number of lessons taught $[\beta=1.86, \mathrm{SE}=0.41]$ were found to be significant predictors of content knowledge at posttest. Three lessons were found to be significant predictors of posttest content knowledge: 1) If Worms Drank Coffee ( $\delta=-9.24$, se-1.98), 2$)$ Heads and Tails $(\delta=4.11, \mathrm{se}=1.86)$ and 3$)$ Chromatography $(\delta=4.61$, se $=1.24)$.

The number of correct science content answers did not vary significantly based on student gender. On the pretest, boys answered an average of $53.5 \%$ of the questions correctly and girls answered an average of $54.6 \%$ of the questions correctly $(\mathrm{t}=1.11, \mathrm{df}=1229, \mathrm{p}=0.27)$. Although students of both genders correctly answered more questions on the posttest than on the pretest, as reported above, there were no significant differences in either the posttest scores or the changes between pretest and posttest (Figure 2). Students from all races and home language backgrounds showed significant improvements in content knowledge when posttest scores were compared to pretest scores (Figure 3).

A statistically significant effect was observed in which the difference between average pretest score and average posttest score varied by grade level $(\mathrm{F}[3,1236]=4.27$, $\mathrm{p}<0.01)$. Specifically, there was a larger difference between pretest and posttest scores among six graders than among seventh and eighth grade students. Sixth graders correctly answered $52.9 \%$ of the knowledge questions at pretest and $73.0 \%$ at posttest; comparable figures for seventh graders were $56.7 \%$ at pretest and $66.4 \%$ at posttest, and for eighth graders, $53.8 \%$ at pretest and $66 \%$ at posttest (Figure 4 ).

Comparison of student pretest and posttest scales on the Simpson Troost Attitude Questionnaire showed little change (Table 4). Although the Motivating Science Class subscale scores were higher on average at posttest compared to scores at pretest, this change was trivial and not significant statis- 
ฮิ ฐ

约

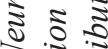

S.

ذे छे

इิ

齐 \&

:

क्षे

ㄷำ

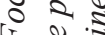

ये 0.5

吾

요용

$\left.+\frac{8}{3}\right)^{2}$

के

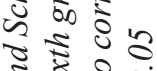

¿ 50

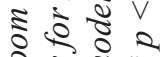

क $5 *$

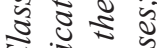

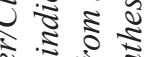

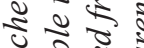

ङ

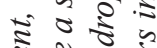

จะ 8

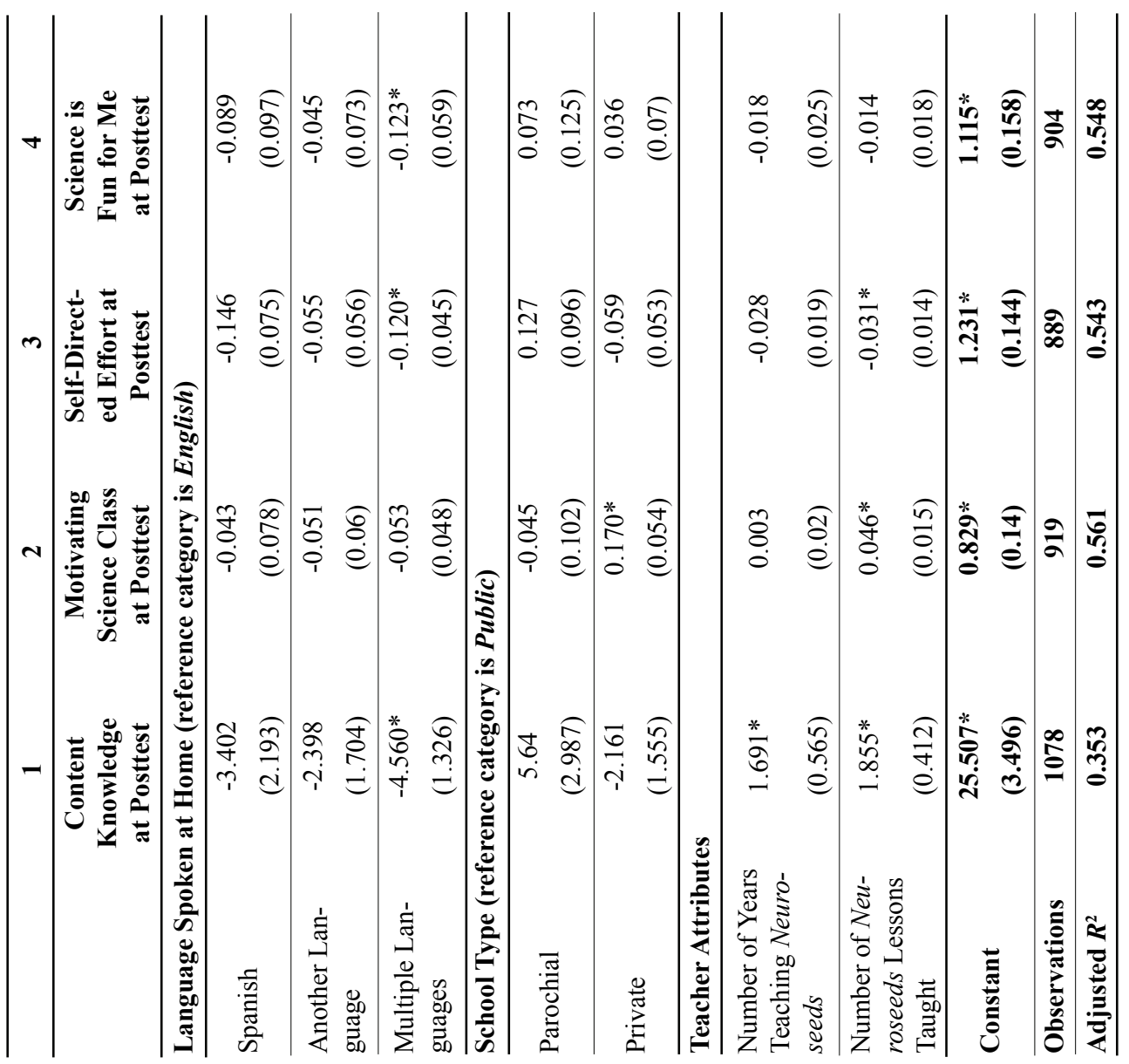

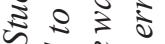

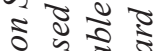

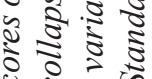

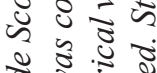

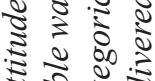

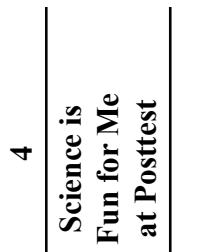

.

(n)

H.

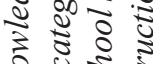

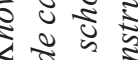

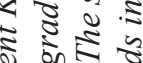

है से चे

के छै

要

0.5 0

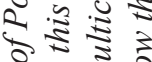

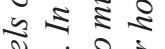

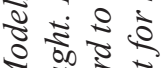

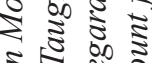

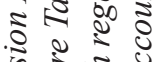

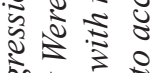

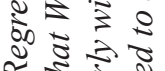

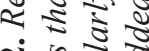

s.

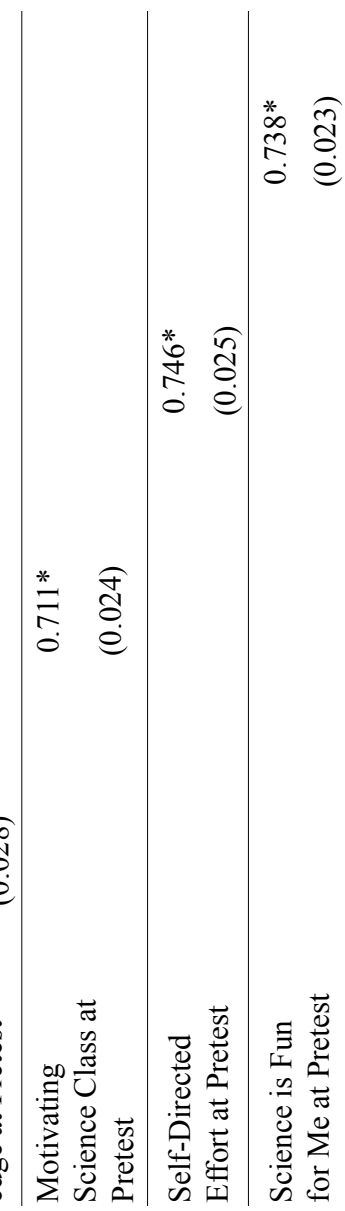

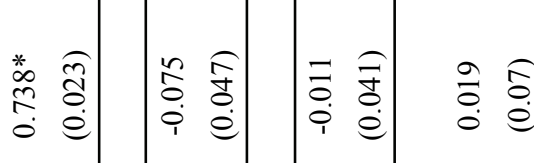

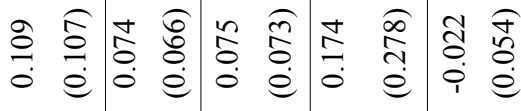

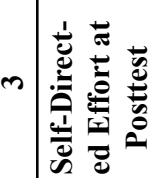

(

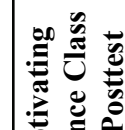

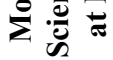

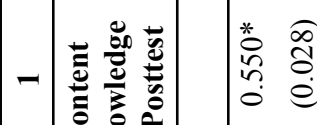

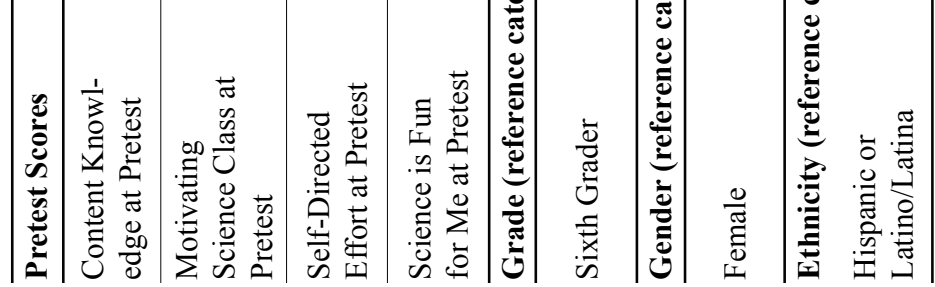

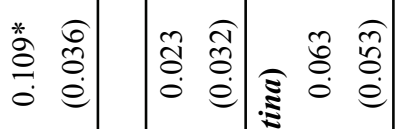

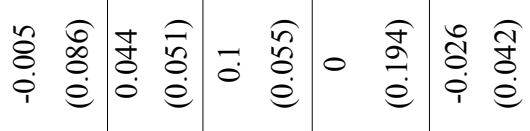

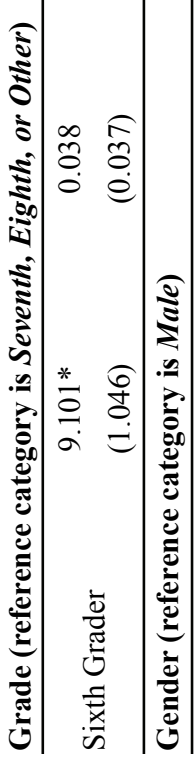

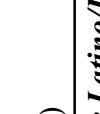

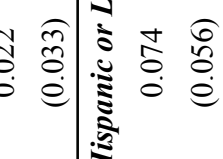

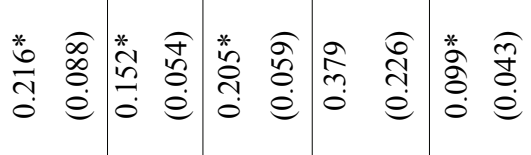




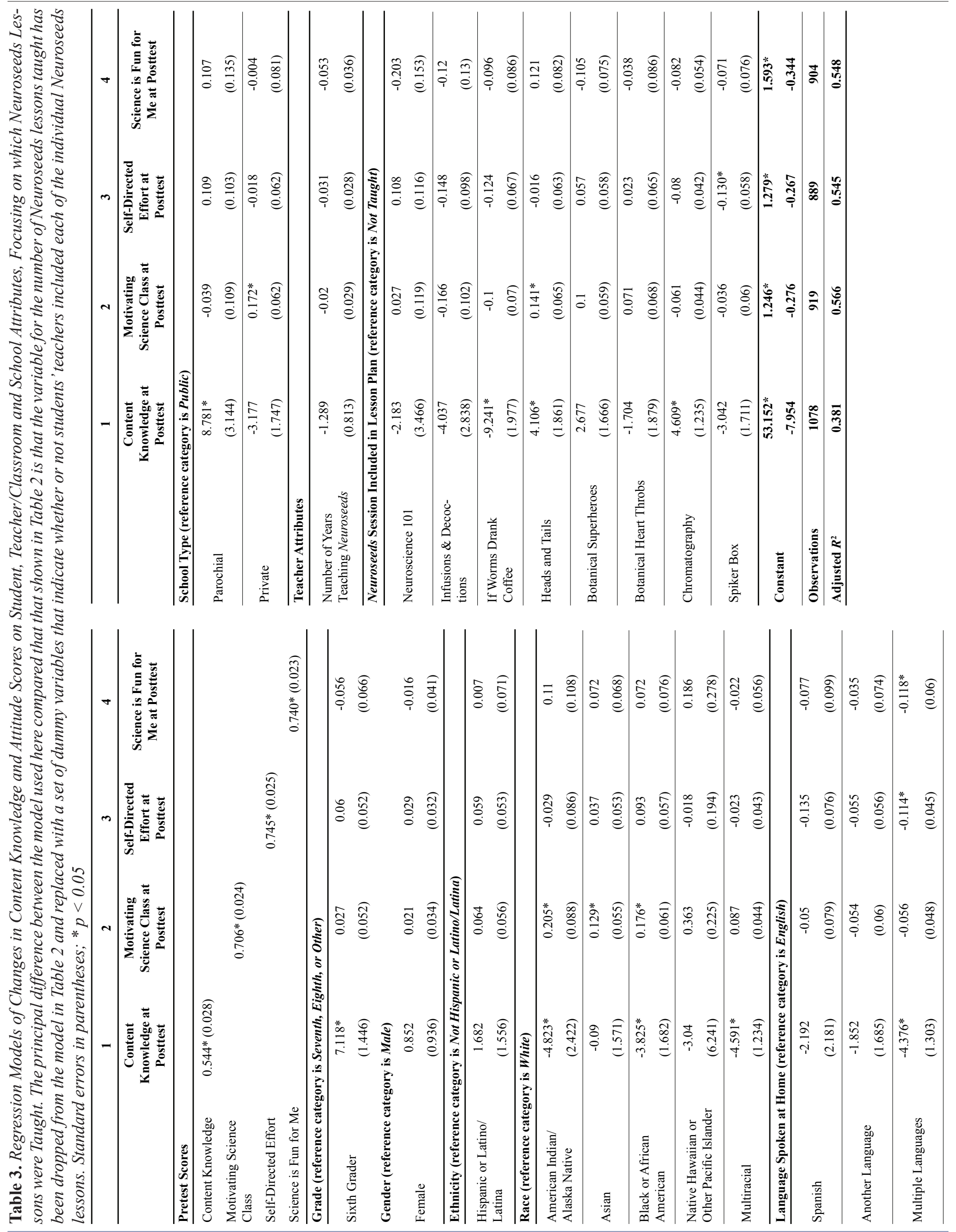


Table 4. Attitude Scales Item Analysis. The same items were used on both the pretest and posttest. Only responses from students with matched pretest and posttest are included.

\begin{tabular}{|c|c|c|c|c|c|c|c|}
\hline & & $\begin{array}{l}\text { Strongly } \\
\text { Disagree } \\
\quad \text { (1) }\end{array}$ & Disagree & Undecided (3) & Agree (4) & Strongly Agree (5) & No Response \\
\hline \multirow{2}{*}{ I would enjoy being a scientist. } & Pre & $6.9 \%(n=86)$ & $10.1 \%(n=126)$ & $35.0 \%(n=436)$ & $27.9 \%(n=347)$ & $15.0 \%(n=187)$ & $5.1 \%(\mathrm{n}=63)$ \\
\hline & Post & $6.7 \%(\mathrm{n}=84)$ & $11.3 \%(n=141)$ & $33.8 \%(n=421)$ & $29.2 \%(n=363)$ & $15.2 \%(\mathrm{n}=191)$ & $3.6 \%(\mathrm{n}=45)$ \\
\hline \multirow{2}{*}{$\begin{array}{l}\text { We learn about important } \\
\text { things in science class. }\end{array}$} & Pre & $1.6 \%(n=20)$ & $2.5 \%(\mathrm{n}=31)$ & $9.4 \%(\mathrm{n}=117)$ & $40.1 \%(n=499)$ & $42.3 \%(n=527)$ & $4.1 \%(n=51)$ \\
\hline & Post & $1.2 \%(\mathrm{n}=15)$ & $2.7 \%(n=33)$ & $9.6 \%(n=120)$ & $40.6 \%(n=505)$ & $43.7 \%(n=544)$ & $2.2 \%(n=28)$ \\
\hline \multirow{2}{*}{$\begin{array}{l}\text { Our science classroom } \\
\text { contains a lot of interesting } \\
\text { equipment. }\end{array}$} & Pre & $1.6 \%(n=20)$ & $5.5 \%(n=68)$ & $18.6 \%(n=232)$ & $40.8 \%(n=508)$ & $29.2 \%(\mathrm{n}=363)$ & $4.3 \%(n=54)$ \\
\hline & Post & $1.5 \%(\mathrm{n}=19)$ & $3.8 \%(n=47)$ & $17.6 \%(n=219)$ & $42.6 \%(n=530)$ & $32.4 \%(n=404)$ & $2.1 \%(\mathrm{n}=26)$ \\
\hline \multirow{2}{*}{$\begin{array}{l}\text { We cover interesting topics in } \\
\text { science class. }\end{array}$} & Pre & $2.8 \%(n=35)$ & $5.3 \%(\mathrm{n}=66)$ & $15.5 \%(n=193)$ & $42.7 \%(n=531)$ & $30.4 \%(n=378)$ & $3.4 \%(n=42)$ \\
\hline & Post & $2.4 \%(n=30)$ & $4.3 \%(n=53)$ & $16.5 \%(n=206)$ & $44.0 \%(n=548)$ & $29.8 \%(n=371)$ & $3.0 \%(\mathrm{n}=37)$ \\
\hline \multirow{2}{*}{ I enjoy science courses. } & Pre & $3.1 \%(n=38)$ & $6.5 \%(n=81)$ & $20.8 \%(n=259)$ & $38.5 \%(n=479)$ & $26.2 \%(n=326)$ & $5.0 \%(n=62)$ \\
\hline & Post & $3.3 \%(n=41)$ & $6.3 \%(\mathrm{n}=79)$ & $21.0 \%(\mathrm{n}=262)$ & $40.2 \%(n=500)$ & $26.3 \%(\mathrm{n}=328)$ & $2.8 \%(\mathrm{n}=35)$ \\
\hline \multirow{2}{*}{$\begin{array}{l}\text { I always try to do my best in } \\
\text { school. }\end{array}$} & Pre & $0.3 \% \quad(n=4)$ & $2.2 \%(\mathrm{n}=27)$ & $6.7 \%(n=84)$ & $30.8 \%(\mathrm{n}=384)$ & $55.7 \%(\mathrm{n}=693)$ & $4.3 \%(n=53)$ \\
\hline & Post & $0.6 \% \quad(n=8)$ & $2.0 \%(\mathrm{n}=25)$ & $8.9(\mathrm{n}=111)$ & $33.4 \%(n=416)$ & $52.1 \%(\mathrm{n}=649)$ & $2.9 \%(n=36)$ \\
\hline \multirow{2}{*}{$\begin{array}{l}\text { We do a lot of fun activities in } \\
\text { science class. }\end{array}$} & Pre & $3.2 \%(n=40)$ & $7.0 \%(\mathrm{n}=87)$ & $20.2 \%(n=251)$ & $40.0 \%(n=498)$ & $25.5 \%(\mathrm{n}=317)$ & $4.2 \%(\mathrm{n}=52)$ \\
\hline & Post & $3.0 \% \quad(\mathrm{n}=37)$ & $6.4 \%(n=80)$ & $19.4 \%(n=242)$ & $41.4 \%(n=515)$ & $27.6 \%(n=344)$ & $2.2 \%(\mathrm{n}=27)$ \\
\hline \multirow{2}{*}{$\begin{array}{l}\text { I consider our science class } \\
\text { attractive and comfortable. }\end{array}$} & Pre & $3.2 \%(n=40)$ & $7.0 \%(n=87)$ & $20.2 \%(n=251)$ & $40.0 \%(n=498)$ & $25.5 \%(\mathrm{n}=317)$ & $4.2 \%(\mathrm{n}=52)$ \\
\hline & Post & $3.5 \%(n=44)$ & $4.7 \%(n=58)$ & $20.7 \%(n=258)$ & $45.5 \%(n=566)$ & $23.1 \%(\mathrm{n}=288)$ & $2.5 \%(\mathrm{n}=31)$ \\
\hline \multirow{2}{*}{$\begin{array}{l}\text { My science teacher makes } \\
\text { good plans for us. }\end{array}$} & Pre & $2.0 \%(\mathrm{n}=25)$ & $2.8 \%(\mathrm{n}=35)$ & $12.7 \%(n=158)$ & $37.6 \%(n=468)$ & $40.8 \%(n=508)$ & $4.1 \%(n=51)$ \\
\hline & Post & $2.2 \%(\mathrm{n}=28)$ & $2.6 \%(\mathrm{n}=32)$ & $12.2 \%(\mathrm{n}=152)$ & $39.2 \%(\mathrm{n}=488)$ & $41.5 \%(n=517)$ & $2.2 \%(\mathrm{n}=28)$ \\
\hline \multirow{2}{*}{$\begin{array}{l}\text { I try hard to do well in sci- } \\
\text { ence. }\end{array}$} & Pre & $0.7 \% \quad(n=9)$ & $0.6 \% \quad(n=6)$ & $8.9 \%(n=111)$ & $32.5 \%(n=405)$ & $53.0 \%(\mathrm{n}=660)$ & $4.2 \%(\mathrm{n}=52)$ \\
\hline & Post & $1.2 \%(\mathrm{n}=15)$ & $1.8 \%(n=23)$ & $9.3 \%(n=116)$ & $35.6 \%(n=443)$ & $49.5 \%(n=616)$ & $2.6 \%(n=32)$ \\
\hline \multirow{2}{*}{$\begin{array}{l}\text { When I fail, that makes me try } \\
\text { that much harder. }\end{array}$} & Pre & $1.5 \%(\mathrm{n}=19)$ & $3.1 \%(\mathrm{n}=39)$ & $16.0 \%(\mathrm{n}=199)$ & $37.1 \%(n=462)$ & $37.0 \%(\mathrm{n}=461)$ & $5.2 \%(\mathrm{n}=65)$ \\
\hline & Post & $1.4 \%(n=17)$ & $3.5 \%(n=44)$ & $19.2 \%(n=239)$ & $36.0 \%(n=448)$ & $36.2 \%(\mathrm{n}=451)$ & $3.7 \%(\mathrm{n}=46)$ \\
\hline \multirow{2}{*}{ I really like science. } & Pre & $4.2 \%(n=52)$ & $7.0 \%(n=87)$ & $23.1 \%(n=288)$ & $33.3 \%(n=415)$ & $26.5 \%(n=330)$ & $5.9 \%(n=73)$ \\
\hline & Post & $4.6 \%(n=57)$ & $6.3 \%(\mathrm{n}=78)$ & $23.7 \%(n=295)$ & $36.5 \%(n=455)$ & $25.1 \%(n=312)$ & $3.9 \%(\mathrm{n}=48)$ \\
\hline \multirow{2}{*}{$\begin{array}{l}\text { I always try hard, no matter } \\
\text { how difficult the work. }\end{array}$} & Pre & $0.9 \%(n=11)$ & $2.8 \%(\mathrm{n}=35)$ & $13.7 \%(n=171)$ & $34.0 \%(n=423)$ & $41.1 \%(\mathrm{n}=512)$ & $7.5 \%(n=93)$ \\
\hline & Post & $1.0 \%(n=12)$ & $2.0 \%(n=25)$ & $13.6 \%(n=169)$ & $34.6 \%(n=431)$ & $41.7 \%(n=519)$ & $7.1 \%(n=89)$ \\
\hline
\end{tabular}

Attitude item analysis $(\mathrm{N}=1,245)$ 


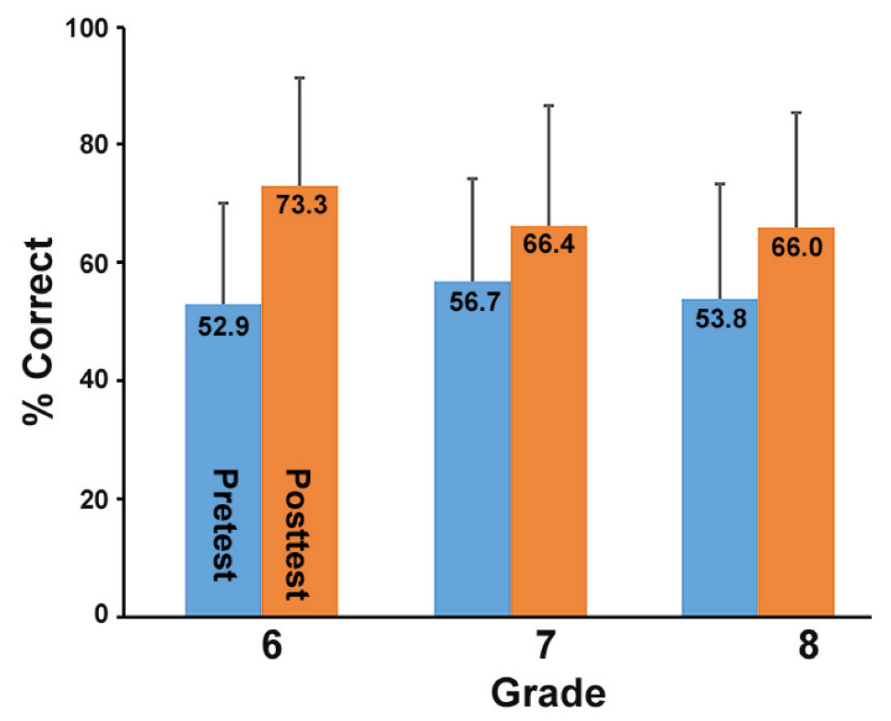

Figure 4. Student content knowledge before (pretest) and after (posttest) using the Sowing the Seeds of Neuroscience lessons based on student grade level. The gain in content knowledge score between pretest and posttest scores among six graders was significantly greater than the gain for seventh and eighth grade students. The numbers within each bar indicates the percent correct before and after the Neuroseeds lessons were by students in different grades. Error bars indicate standard deviation.

tically. Similarly, there was no significant change in the Self-Directed Effort Scale or the Science is Fun for me scale.

\section{DISCUSSION}

Sowing the Seeds of Neuroscience is a new science curriculum that contributed to an increase in middle school students' content knowledge about neuroscience. Middle school students in classrooms that offered the program showed significant acquisition of knowledge about the basic anatomy and physiology of the nervous system, the neuroactive properties of medicinal plants and herbs, and the use of animals in research. Hattie (2009) conducted a meta-analysis of over 800 education intervention studies with the aim of developing an explanation of key influences on student learning. This meta-analysis is a useful tool for evaluating the relative efficacy of different education interventions. The average effect size (Cohen's d) of science programs included in the meta-analysis was 0.40 . Hattie (2009) suggests that interventions with a measured effect size greater than 0.40 are worthy of development as these innovations are likely to enhance student achievement in the real world. The large effect size seen in the pretest-posttest results (Cohen's $d=0.82$ ) suggests that the Sowing the Seeds of Neuroscience program is promising in terms of having a positive impact on student science achievement.

Although sixth graders experienced about the same number of lessons as did students in other grades, sixth grad- ers had both lower pretest scores and higher posttest scores compared to seventh and eighth grade students. The lower pretest scores suggest that sixth graders had less previous exposure to neuroscience, and the higher posttest scores suggests that they took advantage of the lessons to learn more about the neuroscience topics addressed in this curriculum. The greater knowledge gain for sixth graders suggests that it may be advantageous to introduce this program to students earlier rather than later in middle school.

The number of years that teachers used Sowing the Seeds of Neuroscience lessons with their students and the number of these lessons taught to students were predictive of student content knowledge at the posttest. This finding suggests that teachers with more experience teaching the lessons were in a better position to contribute to their students' learning and subsequent performance on the posttest, likely by becoming more adept at preparing the experiments, more knowledgeable about the neuroscience topics addressed in the curriculum, and more familiar with the medicinal herbs that the students were studying. Similarly, we posit that students who worked with more lessons were exposed to repeated discussions of neuroscience and medicinal plants that likely contributed to their greater content knowledge gain.

The number of lessons that teachers taught were also predictive of student knowledge gains between pretest and posttest. Students who benefited from only two lessons experienced an average gain of 10.8 points compared to students who benefited from seven lessons, who had an average gain of 18.5 points. Moreover, there were significant positive correlations between teaching Heads and Tails and Chromatography lessons and students' posttest content knowledge scores. Further investigation will help identify the core set of lessons that would constitute a sufficient dose to achieve curriculum learning objectives.

The regression model indicates that only $35.3 \%$ of the variation in the dependent variable (posttest content knowledge) was predictable from the independent variables in the model. Most of the explanatory power of the model can be attributed to controlling for pretest scores $(\beta=0.55, \mathrm{SE}=0.03)$. Given that this is a singular level model at the student level, rather than a multilevel model, the remaining variance among the results may be due to 1) individual differences across teachers and across students, and 2) socioeconomic status of student families. Specifically, the model did not include variables to account for where the school was located (urban, suburban, or rural) or whether it was public, private, or parochial. More importantly, variables that are indicators of socioeconomic status (e.g., percentage of students who qualify for free or reduced-price lunch) and variables that assess the overall school environment (e.g., the percentage of English language learners, percentage of students of color) were not included.

Although no significant differences in student's attitudes 
about science were observed, this may be because students' attitudes were already quite high on the pretest. In both the Motivating Science Class scale and the Self-Directed Effort scale, mean scores on the pretest were $>4.0$ ("agree") while on the Science is Fun for me scale, mean pretest scores were $>3.5$ (between "unsure" and "agree"). With a series of between two and seven lessons taught over a maximum of twelve weeks, it is possible that this is not a large enough "dose" of hands-on science to change already high science attitudes.

There are several consistencies between the pattern of observed pretest-posttest scores across racial, ethnic and home language categories and data on high school graduation rates in Washington State, an important indicator of the status of the K-12 education system. The finding that students who identified as American Indian/Alaska Native, Black/African American, or multiracial scored lower on the posttest compared to students who identified as Hispanic or Latino/a, Asian, or White is consistent with Washington State's graduation rate disaggregated by race and ethnicity which shows in 2016-2017 (Came et al., 2018), 60.3\% of American Indian students, $71.5 \%$ of Black students, and $79.7 \%$ of multiracial students graduated from high school in four years compared to a $79.3 \%$ graduation rate for all students. Comparatively, $72.7 \%$ of Hispanic students, $87.5 \%$ of Asian students, and $81.9 \%$ of White students graduated from high school in 2016-2017 in four years. Furthermore, the fact that speaking multiple languages at home was found to be predictive of a lower posttest score is consistent with the fact that $57.8 \%$ of students who spoke limited English graduated from high school in four years.

A curriculum of longer duration or one that includes other culturally relevant dimensions, for example ties to social justice (Laughter and Adams, 2012) may also benefit underrepresented students. Also, the hands-on nature of this curriculum may have made the science more engaging and effective for all students. Additionally, as part of this curriculum, students research the medicinal plants used by their families, communities, or ancestors. Teachers discuss traditional Native American, African, South Asian, and Chinese medicines derived from a variety of plants and herbs and indicate that many of these plants have been incorporated into Western medicine (e.g. atropine, aspirin, curare). When students investigate medicinal plants from their own cultures, they may make discoveries that contribute to the scientific literature. In such cases, these data would be confirmed in the Sowing the Seeds of Neuroscience laboratory and students could collaborate with scientists to co-author a paper detailing their findings in a manner similar to Aikenhead and Jegede (1999). Further evaluation is required to understand the relationship between these program components and student learning objective attainment.

All evaluation study designs have limitations and this study is no exception. A quasi-experimental design including two independent groups of students (a treatment group and a comparison group) would improve our ability to draw conclusions about program effectiveness for improving neuroscience literacy in diverse populations of middle school students. Validation of the pretest-posttest is an additional important improvement needed to ensure that the test is accurately measuring targeted neuroscience knowledge gains. Furthermore, a multilevel modeling approach for the statistical analysis would account for the fact that students are best viewed as being nested within classrooms, which are themselves nested in teachers and schools, and thereby strengthen our ability to draw conclusions. In the present analysis, all students in the matched sample were grouped into one large pool, and attributes associated with teachers and schools were included in the singular level model as student-level covariates.

Two other limitations relate to students' exposure to the curriculum. On one hand, we do not know whether any of the students, particularly those in seventh or eighth grade, had previously received the Sowing the Seeds of Neuroscience curriculum. For students who had previously experienced this content, the impact of the lessons may already be factored into their pretests, and any potential gains this year may be diminished. On the other hand, not all students received the same exposure to the curriculum during this year's implementation of the project. None of the teachers taught all eight of the Sowing the Seeds of Neuroscience lessons, and six of the teachers taught fewer than four lessons. While this is a limitation in terms of evaluating the overall impact of the curriculum, it opens the possibility for a future investigation of how variations in program exposure impact student outcomes, particularly in terms of whether some lessons are more impactful than others.

\section{AUTHOR INFORMATION Corresponding Author}

Eric H. Chudler, Ph.D. Center for Neurotechnology. 1414 NE 42nd Street; Box 37. Seattle, WA 98105-6271. Email: chudler@u.washington.edu

\section{Author Contributions}

The manuscript was written through contributions of all authors. All authors have given approval to the final version of the manuscript.

\section{ACKNOWLEDGMENTS}

This work was supported by an NIH Blueprint for Neuroscience Research Award administered by the National Institute on Drug Abuse (Grant number R25DA033011). We 
thank the teachers who participated in pilot testing and Eliza Baird-Daniel, Marcia Johnson-Witter, Elischa Sanders, Luke Allpress, Pranav Venkataraman, Jennifer Trygstad, and Kristen Bergsman who assisted with lesson development, curriculum writing and teacher training. We also thank Michael Coe (data2insight LLC) for help with statistical analysis of the data and for his many helpful comments.

\section{REFERENCES}

Aikenhead, G. S., and Jegede, O. J. (1999). Cross-cultural science education: A cognitive explanation of a cultural phenomenon. Journal of Research in Science Teaching, 36(3), 269287.

Beyerstein, B. L. (1999). Whence cometh the myth that we only use ten percent of our brain? In S. D. Sala (Ed.), Mind Myths: Exploring Everyday Mysteries of the Mind and Brain (pp. 1-24). Chichester (UK): John Wiley and Sons.

Blackwell, L. S., Trzesniewski, K. H., and Dweck, C. S. (2007). Implicit theories of intelligence predict achievement across an adolescent transition: A longitudinal study and an intervention. Child Development, 78(1), 246-263. doi: DOI 10.1111/j.1467-8624.2007.00995.x

Bybee, R., and Bloom, M. V. (2003). Sleep, Sleep Disorders, and Biological Rhythms. Colorado Springs (CO): BSCS.

Bybee, R. W. (1997). Achieving Scientific Literacy. From Purposes to Practices. Portsmouth $(\mathrm{NH})$ : Heinemann.

Bybee, R. W. (2002). Scientific inquiry, student learning, and the science curriculum. In R. W. Bybee (Ed.), Learning Science and the Science of Learning. Arlington (VA): NSTA Press.

Cameron, W., and Chudler, E. (2003). Science and society - A role for neuroscientists in engaging young minds. Nature Reviews Neuroscience, 4(9), 763-768. doi: 10.1038/nrn1200

Came, D., Weaver-Randall, K., and Ireland, L. (2018). Report to the legislature. Graduation and dropout statistics, Washington State Office of the Superintendent of Public Instruction, http://www.k12.wa.us/DataAdmin/pubdocs/ GradDropout/16-17/2016-17GraduationDropoutStatisticsAnnualReport.pdf

Chinn, C. A., and Malhotra, B. A. (2002). Epistemologically authentic inquiry in schools: A theoretical framework for evaluating inquiry tasks. Science Education, 86(2), 175218. doi: $10.1002 /$ sce. 10001

Dekker, S., Lee, N. C., Howard-Jones, P., and Jolles, J. (2012). Neuromyths in education: Prevalence and predictors of misconceptions among teachers. Frontiers in Psychology, 3, 429. doi: 10.3389/fpsyg.2012.00429

Dubinsky, J. M. (2010). Neuroscience education for prekindergarten-12 teachers. Journal of Neuroscience, 30(24), 8057 8060. doi: 10.1523/Jneurosci.2322-10.2010

Freeman, S., O’Connor, E., Parks, J. W., Cunningham, M., Hurley, D., Haak, D., Dirks, C., andWenderoth, M. P. (2007). Prescribed active learning increases performance in introductory biology. CBE Life Sciences Education, 6(2), 132-139.
Gordon, P. R., Rogers, A. M., Comfort, M., Gavula, N., and McGee, B. P. (2001). A taste of problem-based learning increases achievement of urban minority middle school students. Educational Horizons, 79, 171-175.

Haak, D. C., HilleRisLambers, J., Pitre, E., and Freeman, S. (2011). Increased structure and active learning reduce the achievement gap in introductory biology. Science, 332(6034), 1213-1216.

Hattie, J. A. C. (2009). Visible Learning: A Synthesis of Meta-analyses Relating to Achievement. London: Routledge.

Herculano-Houzle, S. (2002). Do you know your brain? A survey on public neuroscience literacy at the closing of the decade of the brain. Neuroscientist, 8(2), 98-110.

Howard-Jones, P. A. (2009). Education and Neuroscience: Evidence, Theory and Practical Application. London: Routledge.

Howard-Jones, P. A. (2010). Introducing Neuroeducational Research: Neuroscience, Education and the Brain from Contexts to Practice. London: Routledge.

Howard-Jones, P. A. (2014). SCIENCE AND SOCIETY Neuroscience and education: myths and messages. Nature Reviews Neuroscience, 15(12), 817-824.

Klisch, Y., Miller, L. M., Beier, M. E., and Wang, S. (2012). Teaching the biological consequences of alcohol abuse through an online game: Impacts among secondary students. CBE Life Sciences Education, 11(1), 94-102. doi: 10.1187/ cbe.11-04-0040

Landes, N. M., and Westbrook, A. L. (2000). The Brain: Understanding Neurobiology Through the Study of Addiction. Colorado Springs (CO): BSCS.

Laughter, J.C. and Adams, A.D. (2012). Culturally relevant science teaching in middle school. Urban Education, 47, 1106-1134.

MacNabb, C., Schmitt, L., Michlin, M., Harris, I., Thomas, L., Chittendon, D., Ebner, T.J., and Dubinsky, J. M. (2006). Neuroscience in middle schools: a professional development and resource program that models inquiry-based strategies and engages teachers in classroom implementation. CBE Life Sciences Education, 5(2), 144-157.

Marzullo, T. C., and Gage, G. J. (2012). The SpikerBox: a low cost, open-source bioamplifier for increasing public participation in neuroscience inquiry. PLoS One, 7(3), e30837.

Michael, J. (2006). Where's the evidence that active learning works? Advances in Physiology Education, 30, 159-167.

Miller, L., Moreno, J., Willcockson, I., Smith, D., and Mayes, J. (2006). An online, interactive approach to teaching neuroscience to adolescents. CBE Life Sciences Education, 5(2), 137-143.

National Governors Association Center for Best Practices, C. o. C. S. S. O. (2010a). Common Core State Standards (English Language Arts). Washington, D.C.: National Governors Association Center for Best Practices, Council of Chief State School Officers. 
National Governors Association Center for Best Practices, C. o. C. S. S. O. (2010b). Common Core State Standards (Mathematics). Washington, D.C.: National Governors Association Center for Best Practices, Council of Chief State School Officers.

Osborne, J., Simon, S., and Collins, S. (2003). Attitudes towards science: a review of the literature and its implications. International Journal of Science Education, 25(9), 10491079. doi: 10.1080/0950069032000032199

Owen, S. V., Toepperwein, M. A., Marshall, C. E., Lichtenstein, M. J., Blalock, C. L., Liu, Y., Pruski, L.A., and Grimes, K. (2008). Finding pearls: Psychometric reevaluation of the Simpson-Troost Attitude Questionnaire (STAQ). Science Education, 92(6), 1076-1095. doi: 10.1002/sce.20296

Pickering, S. J., and Howard-Jones, P. (2007). Educators' views on the role of neuroscience in education: Findings from a study of UK and international perspectives. Mind Brain and Education, 1(3), 109-113. doi: 10.1111/j.1751228X.2007.00011.x

Schwartz-Bloom, R. D., Halpin, M. J., and Reiter, J. P. (2011). Teaching high school chemistry in the context of pharmacology helps both teachers and students learn. Journal of Chemical Education, 88(6), 744-750. doi: 10.1021/ ed100097y

Stark, L. A., and Pompei, K. (2010). Making genetics easy to understand. Science, 327(5965), 538-539. doi: DOI 10.1126/ science. 1183029

States, N. L. (2013). Next Generation Science Standards: For States, By States. Washington, D.C.: The National Academies Press.

Straus, K. M., and Chudler, E. H. (2016). Online teaching resources about medicinal plants and ethnobotany. CBE Life Sciences Education, 15(4).

Tai, R. H., Liu, C. Q., Maltese, A. V., and Fan, X. T. (2006). Planning early for careers in science. Science, 312(5777), 1143-1144. doi: 10.1126/science. 1128690

Tanner, K. D. (2010). Order matters: Using the 5E model to align teaching with how people learn. CBE Life Sciences Education, 9(3), 159-164. doi: 10.1187/cbe.10-06-0082

Taraban, R., Box, C., Myers, R., Pollard, R., and Bowen, C. W. (2007). Effects of active-learning experiences on achievement, attitudes, and behaviors in high school biology. Journal of Research in Science Teaching, 44(7), 960-979. doi: 10.1002/tea.20183

Trowbridge, L. W., Bybee, R. W., and Powell, J. C. (2004). Teaching Secondary School Science. Strategies for Developing Scientific Literacy. Upper Saddle River (NJ): Pearson Education, Inc. 